\title{
Liver and gastrointestinal function in pregnancy
}

\author{
Carol A. Seymour* \\ M.A. (Cantab.) M.A. (Oxon), M.Sc., M.R.C.P. \\ V. S. Chadwick $\dagger$ \\ M.A. (Cantab.) M.D., M.R.C.P. \\ * Departments of Medicine, University of Cambridge, and \\ $\dagger$ Royal Postgraduate Medical School, Hammersmith Hospital, London
}

\begin{abstract}
Summary
Difficulties arise in the interpretation of liver tests in the pregnant subject, since some values increase (alkaline phosphatase) whilst others remain unchanged (transaminases) or fall during pregnancy. The diagnosis and management of some causes of jaundice in pregnancy, such as viral hepatitis, gall stones, benign intrahepatic cholestasis and acute fatty liver of pregnancy are discussed.

Little is known about the commonest symptoms of pregnancy (nausea, vomiting and constipation) other than that they might be due to hormonally induced alteration of sphincter tone. However, pre-existing bowel disease has a greater effect on pregnancy. Fertility is reduced in poor nutritional states (e.g. coeliac and Crohn's diseases) and an increased occurrence of spontaneous abortion has been noted. For inflammatory bowel diseases, the time of onset is important in determining the outcome of pregnancy. Relapse in the disease is commonest in the first trimester and in the puerperium. Treatment of these conditions is essentially as in the non-pregnant subject. The controversial subject of sulphasalazine and steroid usage in pregnancy is discussed.
\end{abstract}

\section{Normal liver function in pregnancy}

It is perhaps notable that more is known about pregnancy and liver disease than about the impact of pregnancy upon the normal liver. In a normal pregnancy, hepatic function is not significantly impaired, although little is known about the detailed function of the liver (Hytten and Leitch, 1971). The occasional finding of abnormal results of liver function studies performed on pregnant women with no obvious clinical symptoms of liver disease, has raised the question 'can the normal laboratory values be used as standards for interpretation of liver function studies in pregnant subjects?' This is particularly important since some clinical features are common both to pregnancy and liver disease. These include the development of vascular spiders and palmar erythema, which may be due to the physiological increase in circulating oestrogens. These disappear within a few months of termination of pregnancy (Bean et al., 1949).

Biochemical tests show varying changes throughout the gestational period. The liver function studies carried out in 600 normal pregnant women during gestation and labour were normal during the first trimester (McNair and Jaynes, 1960). Table 1 shows

TABLE 1. Changes during normal pregnancy

1. Progressive decrease towards term

Haemoglobin

Haematocrit

Serum proteins/albumin $/ \gamma$-globulin

Serum iron

2. Progressive increase towards term

Spider naevi, palmar erythema

Total white count

ESR

Serum alkaline phosphatase

Serum cholesterol and lipids

Serum fibrinogen

BSP retention

Cardiac output

Plasma and total blood volume

3. Occasional increase not dependent on stage of gestation Urinary bile pigments

Serum bilirubin

4. No changes

Serum transaminases

Prothrombin

Liver blood flow

5. Minor changes

Liver displacement by enlarging uterus

Liver histology

some of the variations occurring during a normal pregnancy. Haematological parameters are associated with a progressive fall in circulating levels. Total serum protein concentration falls by $10 \mathrm{~g} / \mathrm{l}$ in the first 16-20 weeks of pregnancy and remains constant thereafter. Most of this change is due to a fall in serum albumin concentration. A small reduction in $\gamma$-globulin (mainly IgG) also occurs but is less 
marked. Fibrinogen and the $\alpha$ - and $\beta$-globulin fraction tend to increase (Hytten and Leitch, 1971). Attention is now focused on the pregnancy-associated proteins produced by the trophoblast to indicate abnormalities in pregnancy (Lin et al., 1977). More importance is attached to enzyme rises occurring throughout pregnancy, since these are significant because of the associated increase in plasma volume. There is a progressive increase in alkaline phosphatase activity, which occurs mainly in the third trimester and which is often sufficient to produce levels which exceed the accepted upper limit of normal for non-pregnant individuals (Wetstone et al., 1958) The increase is mainly due to placental alkaline phosphatase and it may be necessary to identify the source of the enzyme by electrophoresis or immunochemical methods (Sussman, Bowman and Lewis, 1968; Romslo, Sagen and Haram, 1975). The issue may also be clarified by measuring enzyme levels which are increased in hepatic disease but not in pregnancy or in the puerperium, such as $\gamma$-glutamyl transpeptidase (Walker et al., 1974). Total serum cholesterol levels are raised during pregnancy but esterification is normal and the concentrations are normal in fetal blood. This should not be taken to indicate liver or underlying hyperlipaemic conditions without other evidence (McNair and Jaynes, 1960).

The dye, bromsulphthalein (BSP) can be used to study hepatic function in more detail. This dye is removed by the liver and excreted into bile and, as it is not transported across the placenta, its fate after injection is the same, qualitatively, in the pregnant as in the non-pregnant subject. When BSP is infused at different rates and the plasma concentration measured at intervals, subsequent calculation allows measurement of 2 independent processes of storage by liver cells and active secretion into bile. Storage may increase by $122 \%$ in the last trimester of pregnancy and return to normal in the first week after delivery. Conversely, active secretion to bile is reduced by $27 \%$ during the latter half of pregnancy and also returns to normal in the puerperium (Combes et al., 1963). During pregnancy there is an increase in BSP uptake from plasma and in return of the dye to the plasma, although some of this can be explained by increased binding to proteins (Crawford and Hooi, 1968).

Some tests of liver function change only slightly during pregnancy and these will therefore signal abnormalities when liver disease occurs during pregnancy; these include bilirubin (McNair and Jaynes, 1960), although some series have shown an increase. Serum transaminases (Friedman and Lapan, 1961) and prothrombin as well as 5'nucleotidase and $\gamma$-glutamyl transpeptidase remain normal. However, because of this difficulty in interpretation of the results of laboratory tests, it may be necessary to perform liver biopsy more often in pregnant than non-pregnant subjects with jaundice. Liver tissue taken during normal pregnancy shows only minor non-specific light microscopic changes such as increased glycogen (Ingersley and Teilum, 1945). Electron microscopy in the last trimester shows some changes in endoplasmic reticulum, but these have also been observed in patients taking oral contraceptives (Perez et al., 1971). Many of these changes mentioned above can be reproduced by oestrogen therapy (Mueller and Kappas, 1964).

Extensive reviews of jaundice occurring in pregnancy (Haemmerli, 1966) estimated that jaundice occurs with $1 / 1500$ gestations and the commonest causes were: viral hepatitis $(40 \%)$, recurrent intrahepatic cholestasis $(21 \%)$, gall stones $(6 \%)$, although these incidences vary slightly from country to country. Table 2 shows a classification of jaundice

TABle 2. Classification of icterus gravidarum

A. Jaundice peculiar to pregnancy:

Hyperemesis gravidarum

Toxaemia

Intrahepatic cholestasis

Acute fatty liver

Hydatidiform mole

Megaloblastic anaemia

Haemolytic anaemia

\section{B. Jaundice in pregnancy:}

(i) Usual forms

Viral hepatitis

Hepatotoxic drugs

Gall stones

Congenital transport defects - Gilbert's, Dubin-JohnsonSprinz

Haemolytic disorders

(ii) Jaundice in medical complications:

Pyelonephritis

Tetracycline

Abortions with septicaemia

C. Pregnancy superimposed upon pre-existing liver disease: Chronic active hepatitis

Cirrhosis

Wilson's disease

in relation to pregnancy (Sherlock, 1968). It is assumed that circulating enzyme levels correlate well with tissue enzyme activities, this really only applies to enzymes of the plasma membrane and biliary canaliculi. However, distinct biochemical patterns are recognized which suggest hepatocellular (predominant increase in transaminase activity) or obstructive liver disease (predominant increase in alkaline phosphatase and $\gamma$-glutamyl transpeptidase activities). 


\section{Jaundice peculiar to pregnancy}

Apart from minor changes associated with hyperemesis gravidarum and with the pre-eclampsia, major differential diagnosis lies between benign intrahepatic cholestasis and acute fatty liver of pregnancy.

\section{Benign intrahepatic cholestasis of pregnancy}

Haemmerli's series (1966) is particularly concerned with this. There is much geographical variation in the incidence of this disease which has a peculiar preference for Scandinavian countries and Chile. Its aetiology is uncertain, but a familial tendency may be present (Reyes, Ribalta and Gonzalez-Ceron, 1976). Summerskill and Walshe (1959) first described this condition in non-pregnant subjects and information on 57 patients has subsequently been reported (De Pagter et al., 1976). Thus, this condition during pregnancy is troublesome to patient and obstetrician because of pruritus, and interesting to the physician because of the relationship to the other benign recurrent intrahepatic cholestases.

In classical presentation, generalized pruritus appears in the second half of pregnancy although the onset could occur as early as 6 weeks. This is followed within a few weeks by jaundice, but in its mildest form pruritus is present without icterus. The general health of the patient is well preserved and constitutional features of the kind found in hepatitis are absent. The liver and spleen are impalpable. Within one to 2 weeks of delivery, the pruritus disappears. The prognosis is excellent, but the condition may recur in subsequent pregnancies and a similar syndrome can exist in patients taking oral contraceptives (Drill, 1974).

The biochemical pattern is that of cholestasis with slight increase in serum bilirubin usually less than $100 \mu \mathrm{mol} / 1(6 \mathrm{mg} \%)$. The increased levels of alkaline phosphatase can be distinguished from the physiological rise in placental alkaline phosphatase, by a concomitant increase in $\gamma$-glutamyl transpeptidase. Serum transaminases are only slightly increased (always less than 250 i.u./l). In the absence of a past or family history, it may be necessary to distinguish this condition from the early phase of acute fatty liver, cholestatic phase of viral hepatitis or gall stones. Liver biopsy may be indicated. Histology is usually normal apart from centrilobular cholestasis, hepatocellular necrosis and inflammation are absent. Electron micrographs show some dilatation, blunting and swelling of microvilli found with all forms of cholestasis.

The aetiology of this condition is not certain. It is thought to be due to exaggeration of the physiological changes occurring with normal pregnancy with an increase in circulating oestrogenic steroids, and concomitant reduction in excretion. The fact that a similar situation exists with oral contraceptives and menopausal cholestasis, suggests that impairment is due to oestrogenic components (Ockner and Davidson, 1967; Urban, Frank and Kern, 1968), although progestins may play a synergistic role (Perez and Gorodisch, 1974).

In all these syndromes, the condition as far as the mother is concerned is benign, because symptom free periods exist when the patient is clinically, biochemically and histologically normal. Some evidence shows that there is an increased incidence of prematurity, fetal distress and perinatal death (Reid et al., 1976). Management from the maternal side is uncomplicated. The patient can be reassured that itching and jaundice will resolve after delivery. Pruritus can be controlled using cholestyramine, a non-absorbable basic anion-exchange resin which binds bile acids. The reason why this is often reported as ineffective by the patient, is that an inadequate dose has been ingested. Often the patient prefers to continue with pruritus than to have bowel symptoms related to taking cholestyramine. Enzymeinducing agents, such as barbiturates, have also been used to control pruritus. Evidence from enzyme induction is indirect. Cholesterol is converted to bile acids and the first step in this synthesis is an hydroxylation which is probably rate-limiting for the reaction. This may already be stressed during pregnancy. Although this hydroxylation is similar to that described in connection with steroid hydroxylation and certain drugs, it is not certain that cytochrome $P 450$ is a component of the bile acid system. Similar studies in patients with primary biliary cirrhosis showed no change in circulating bile salt levels, even though evidence of enzyme induction was confirmed by altered antipyrine half-life (C. A. Seymour and J. L. Peters, unpublished data). Thus, the major effect on pruritus in pregnancy is probably by sedation. There is no indication in this disease for termination, and subjects should avoid oral contraceptives and should be warned that the condition could occur in subsequent pregnancies.

Management of the fetus is more difficult. Induction of labour should be considered after 37 weeks. Measurement of oestriol levels was found not to be a good index of fetal well-being and it has been suggested that retained maternal bile acids could play a role in fetal distress (Laatikainen, 1975). Thus, cholestyramine might well improve the prognosis as well as maternal discomfort if adequate doses are taken ( $27 \mathrm{~g} /$ day).

\section{Acute fatty liver of pregnancy}

This rare, though serious, condition was first described by Sheehan (1940). He suggested that there was a yellow atrophy of liver in pregnancy. This has 
subsequently been called 'acute fatty liver of pregnancy' (Ober and Le Compte, 1955). Typically, the patient develops jaundice, nausea, vomiting, haematemesis, abdominal pain and headaches during the last trimester. Haemmerli's (1966) series does report some cases as early as 30 weeks. The outcome of the illness is similar to acute fulminant hepatic failure and may be fatal within a few days or weeks. The mother becomes progressively jaundiced and uraemic, and coma and death are the usual outcome. A stillborn fetus is common.

The clinical picture may be indistinguishable from acute fulminant viral hepatitis. The biochemical pattern is of increased serum bilirubin, reduced prothrombin time, uraemia and acidosis. However, liver histology is quite distinctive showing marked centrilobular fat deposition, little or no hepatocellular necrosis (expected with viral hepatitis) or inflammatory reaction. The fat occurs within small vacuoles and the nuclei are centrally placed. Electron microscopy reveals cystic changes in the endoplasmic reticulum (Duma et al., 1955). Abnormalities may also occur in the renal tubules (Ober and Le Compte, 1955) and pancreas.

The aetiology of this condition is uncertain but it has been related to protein malnutrition (Duma $e t$ $a l ., 1965)$ and to depression of protein synthesis induced by drugs such as tetracycline both during pregnancy (Kunelis, Peters and Edmundson, 1965) and at other times (Peters et al., 1967). This drug should be avoided when treating infection in pregnancy, since fatty change in liver tissue and death has been well documented (Sherlock, 1968).

The prognosis of this condition is poor and optimum management is unknown. It is essentially supportive as for other causes of acute fulminant hepatic failure as outlined by Sherlock (1975). Large amounts of glucose may need to be given to avoid profound hypoglycaemia (Breen et al., 1970). Other complications arise, and cases of disseminated intravascular coagulation have been reported, with good recovery after administration of heparin (Cano et al., 1975). Vitamins and lipotropic substances, including choline, may be given but have not proved of great value. The mortality of acute fatty liver is very high although survivors make good recovery. Miller (1977) reported that in 81 cases studied between 1934 and 1976, maternal mortality was $77 \%$ and fetal mortality was $76 \%$. There was no significant change in these figures, if cases occurring secondary to tetracycline were excluded. Early Caesarean section has been advocated (Haemmerli, 1966) to give the best chance of survival for both mother and fetus. This issue has not been conclusively resolved but where Caesarean section is indicated, then it should be with epidural rather than general anaesthesia. Unlike the recurrent intrahepatic cholestasis, it is not certain that the condition recurs in subsequent pregnancies (Breen et al., 1972).

\section{Viral hepatitis in pregnancy \\ Case illustration}

A 31-year-old primigravida was admitted in labour; a normal male infant weighing $3.7 \mathrm{~kg}$ was delivered and breast feeding was established. Subsequently, a history of a rash 12 days, arthritis 11 days and fever 7 days before admission was obtained. Paracetamol was the only drug she had taken. She had a stable relationship with a common-law husband. Examination showed a healthy woman with a temperature of $38^{\circ} \mathrm{C}$, no clinical jaundice, tenderness in the right upper abdominal quadrant but no enlargement of the liver. There was pain and limitation of movement in the elbows and shoulders. Investigations showed a haemoglobin of $14 \mathrm{~g}$, a white cell count of $106 \times 10^{9} / 1$, platelet count of $395 \times 10^{9} / 1$, bilirubin $17 \mu \mathrm{mol} / 1$ (normal < 14), alkaline phosphatase 504 i.u./l (normal $<130$ ) and SGOT 200 i.u./l (normal < 40). The hepatitis B surface antigen was positive at a titre of $1: 32$. A diagnosis of acute type B hepatitis with prodromal rash and arthritis was made.

Investigations of the infant who had been breast fed for 3 days showed that his blood was negative for both hepatitis B surface antigen and antibody은 The hepatitis B surface antigen was not found in the breast-milk. Prophylaxis with $0.5 \mathrm{ml}$ of hyper? immune $\gamma$-globulin was instituted, since infants born to mothers with acute hepatitis $B$ in the third trimester are at risk.

Investigations of the common-law husband who was asymptomatic revealed a bilirubin of $4 \mu \mathrm{mol} / 1$, alkaline phosphatase of 107 i.u./l and a raised SGOT at 138 i.u./l. His blood was strongly positive for hepatitis B antigen at a titre of 1:1024 and the antigen was also found in the seminal fluid. Since he was suspected of being a chronic $\mathrm{HB}_{\mathrm{s}} \mathrm{Ag}$ carrier, and because he had abnormal enzymes, liver biopsy was performed which showed chronic persistent hepatitis.

The patient herself remained relatively well, the SGOT and alkaline phosphatase returned to normal within 3 weeks, the hepatitis B surface antigen disappeared from her blood and the hepatitis B surface antibody appeared.

This case illustrates the typical uncomplicated course of hepatitis in pregnancy, the importance of trying to identify the probable source of infection, which may be within the family unit and the current clinical practice aimed at preventing the development of hepatitis in the infant.

\section{Discussion}

Viral hepatitis is the commonest cause of jaundice in pregnancy although the actual incidence of this 
disease is not increased in pregnancy (Haemmerli, 1966). In developed countries, the severity of hepatitis is not increased by the pregnancy and the mortality is less than $0.5 \%$ (Haemmerli, 1966); however, in developing countries, pregnancy is associated with a high incidence of severe or fulminant hepatitis. For instance, in Iran, the mortality is $60 \%$ and the incidence of fulminant hepatitis is $50 \%$ (Borhanmanesh et al., 1973). Hepatitis is associated with an increase in prematurity to the order of $20 \%$ and fetal mortality is overall about $7 \%$ (abortions $3.5 \%$, prematurity $3.0 \%$ and full-term $0.5 \%$ ) (Haemmerli, 1966). There is no evidence that viral hepatitis leads to an increase in the number of congenital malformations.

The transmission of hepatitis from mother to fetus rarely occurs by the transplacental route (Rotthauwe, 1974) but probably occurs in the perinatal period via cord blood, birth contact or breast feeding and the risk of transmissibility is increased if the mother has acute hepatitis and less high if she is a carrier of hepatitis (Skinhoj, Cohn and Bradburne, 1976). The presence of the ' $\mathrm{e}$ ' antigen in maternal blood is associated with an increased risk of materno-fetal transmission (Okada et al., 1976). Infected neonates tend to become chronic $\mathrm{HB}_{\mathrm{s}} \mathrm{Ag}$ carriers (Schweitzer et al., 1973) but the incidence of chronic hepatitis and the development of cirrhosis is unknown.

Treatment of the mother with hepatitis is conservative; termination is not recommended and steroids are ineffective. Infants of mothers with acute hepatitis or who are chronic carriers of $\mathbf{H B}_{\mathrm{s}} \mathbf{A g}$ should receive hyperimmune $\gamma$-globulin and breast feeding should be avoided.

Fulminant hepatitis is associated with $100 \%$ fetal mortality and a $70-80 \%$ maternal mortality. There is no proved beneficial effect of steroids, plasma exchange, hyperimmune globulin, extra-corporeal perfusions, etc., but supportive treatment to maintain blood sugar and to correct coagulation disorders is essential. Survivors rarely develop chronic liver disease. Chronic active hepatitis is associated with a marked decrease in fertility (Huchzermeyer, 1971), but effective therapy with steroids and azathioprine has resulted in increased fertility and successful pregnancy in many such patients.

\section{Gall stones in pregnancy}

$90 \%$ of gall stones are predominantly cholesterol in composition and the remaining $10 \%$ are pigment stones. In the non-pregnant population cholesterol stones are associated with the secretion of 'lithogenic bile' in which bile is supersaturated with cholesterol as a result of a defect in bile salt secretion or an increase in biliary cholesterol secretion. Both female sex hormone therapy and parity are recognized as being predisposing factors for cholesterol gall stone formation. Exogenous oestrogens depress bile salt secretion and increase the saturation index of cholesterol in bile (Lynn et al., 1973; Bennion et al,. 1976). The prevalence of gall stones is increased with oral contraceptives and oestrogen therapy and in the oestrogen-sensitive recurrent intrahepatic cholestasis of pregnancy (Adlercreutz and Tenhunen, 1970). However, although the relationship between gall stone disease and female sex hormone therapy is well established, that between parity and the prevalence of gall stones is in dispute, a positive association has been reported by some (Van der Linden, 1961) and an absence of any correlation reported by others (Sampliner et al., 1970). Increased serum cholesterol is characteristically found in pregnancy and it has been suggested that this is associated with increased biliary cholesterol secretion. However, there is no evidence for increased cholesterol saturation of bile in pregnant humans. Whether decreased gall bladder contractility associated with high serum progesterone levels leads to bile stasis and predisposes the gall stones is conjectural.

Gall stones rarely cause obstructive jaundice during pregnancy, but biliary colic and cholecystitis are more common. Investigation of patients with suspected gall bladder disease should involve greyscale ultrasonography as the initial non-invasive investigation. If this indicates the presence of stones, then cholecystectomy should be considered. In the absence of a positive ultrasound, the non-jaundiced patient should be treated conservatively with nasogastric suction, intravenous fluids and antibiotics and the biliary tract investigated later by an oral cholecystogram. If the patient is jaundiced then a negative ultrasound should be followed by a liver scan and transhepatic or endoscopic cholangiography. The incidence of cholecystectomy in pregnancy is less than $0.1 \%$ in the U.S.A.

\section{Gastrointestinal problems in pregnancy \\ Common gastrointestinal symptoms in pregnancy}

Common gastrointestinal symptoms in pregnancy include altered appetite and pica, tooth and gum problems, excessive salivation, heartburn, nausea, vomiting, indigestion, constipation and bleeding or prolapsing haemorrhoids. The physiological basis underlying these symptoms is not completely understood.

Gastro-oesophageal reflux has a prevalence of about $30-50 \%$ and is worse in the third trimester. There is a progressive reduction in lower oesophageal sphincter pressure during pregnancy (van Thiel et al., 1977) and in vitro, progesterone is known to inhibit gastrin-stimulated lower oesophageal sphincter muscle contraction (Fisher et al., 1976). Similarly, the contraceptive pill reduces lower oesophageal pressure in vivo. Gastric acid secretion is said to be 
reduced in the middle trimester but later in pregnancy gastric $\mathrm{pH}$, basal and peak acid outputs and plasma gastrin were found to be no different from the normal non-pregnant female population (van Thiel et al., 1977). Symptoms of reflux thus correlate best with this reduction in lower oesophageal sphincter pressure and although the incidence of hiatus hernia may reach as high as $50 \%$ in late pregnancy, the correlation between this and reflux is not well established. Treatment of reflux is conventional, with avoidance of stooping and bending, raising the head of the bed on blocks, limiting the size of meals and taking antacids. Anti-cholinergic agents are probably contra-indicated since they reduce the lower oesophageal sphincter pressure and anti-cholinergic preparations have not been established as being safe in pregnancy.

Symptoms of peptic ulcer tend to remit during pregnancy and to be exacerbated in the puerperium (Clark, 1953) and this is in keeping with the known effects of oestrogens in promoting ulcer healing (Truelove, 1960). Complications of peptic ulcer are thus rare in pregnancy although the incidence of acute peptic ulceration and gastrointestinal bleeding is high in pre-eclampsia and eclampsia (Langmade, 1956). The indications for surgery after, for instance, perforation of the peptic ulcer are the same in the pregnant and non-pregnant situation.

The incidence of constipation in pregnancy is not well established, in one series (Levy, Lemberg and Sharf, 1971) $53 \%$ of pregnant women had no change in bowel habit, $34 \%$ had an increased frequency, $11 \%$ a decreased frequency and only $1.5 \%$ required laxatives. The mechanism of constipation in pregnancy is thought to be related to the effects of progesterone in inhibiting smooth muscle tone in the bowel (Kumar, 1962) and to the mechanical effects of the uterus and fetus (Avery-Jones and Gummer, 1960), effect of previous pregnancies on muscles and pelvic floor (Turrell, 1969) and the presence of painful anal lesions (Atkinson and Hudson, 1970). Investigations of constipation should be limited to proctoscopy and rectal examination, and treatment with bran, magnesium hydroxide and hydrophilic colloids is recommended.

\section{Pregnancy and pre-existing bowel disease}

Some diseases which may cause malabsorption particularly of $B_{12}$ and folate, such as coeliac disease, ulcerative colitis and Crohn's disease, occur between the ages of 20 and 40 years and so are likely to coincide with pregnancy. The important questions arising from this are: whether disease of the bowel predisposes to subfertility, whether the outcome of pregnancy is influenced by the presence of the disease and, finally, whether pregnancy affects the course of the disease.

\section{Coeliac disease}

Megaloblastic anaemia is associated with preg nancy and many factors interfere with folate metabolism and lead to deficiency even in patients who are taking a normal diet. It is therefore difficult to know when a low folate level in pregnancy signals pathology. Folate deficiency is common in tropical countries and, in some cases, responds to administration of the vitamin. However, folic acid deficiency is probably a reversible cause of spontaneous abortion (Martin, Harper and Kelso, 1965). A small proportion of patients with iron and folate deficiency presenting in pregnancy will have undiagnosed gluten-sensitive enteropathy (Joske and Martin, 1971). However, successful pregnancies can occur before and after diagnosis of coeliac disease, as has been shown with the 15 patients reviewed by Ogborn (1975). Although infertility was a feature of active coeliac disease (Morris, Adjukiewicz and Read, 1970), this did not appear in Ogborn's series. An increased incidence of spontaneous abortion has been shown in patients with low folic acid levels (Martin et al., 1965) which could explain the $20 \%$ spontaneous abortion in untreated patients. Unrecognized coeliac disease is the cause of spontaneous abortion in the first trimester. Treatment of the enteropathy appears to improve infertility in some cases (Morris et al., 1970). A strict gluten-free diet, laboratory assessment, correction of deficiencies and serial assessment of the placenta seem to improve the outcome of pregnancy in the patient with coeliac disease. In many cases the mother may just suffer severe iron deficiency anaemia throughout pregnancy, despite treatment with haematinics, and often the presenting features of diarrhoea and skin rash may not be manifest until after delivery.

\section{Ulcerative colitis}

This disease of large bowel is characterized by ulceration of intestinal mucosa and associated with rectal blood and mucus, diarrhoea and abdominal pain. It may have some local and systemic associations. Because of the problems of prolonged followup, it is often difficult to assess the effect of colitis upon fertility of a woman in her reproductive years. Fertility may be impaired by the presence of colitis (Maddix, 1962). Although this is still questionable, $31-49 \%$ of patients of childbearing age have become pregnant (de Dombal et al., 1965).

The outcome of pregnancy is easier to ascertain. Most reviews agree that, in general, ulcerative colitis does not have a deleterious effect on a pregnancy. In one series (Webb and Sedlack, 1974), there was no difference in spontaneous abortions between women with ulcerative colitis and those in the normal population. In 6 major series reviewed by Fielding (1976), there were 610 pregnancies in 399 
patients. Live births were the outcome of $83 \%$ of gestations. Spontaneous abortion figures were similar to those in the general population $(9 \%) ; 1 \%$ of infants had congenital abnormalities and $2 \%$ were stillbirths. This is not so very different from the normal population.

There is less agreement between authors when considering the effect of pregnancy upon the colitis. Patients are usually considered in 4 categories according to the time when the colitis is active: Category (1) inactive at conception; (2) active at conception; (3) onset during gestation; (4) onset during puerperium.

From Fielding's series of 266 pregnancies, 35\% were in Category 1 and relapses occurred in the first trimester or in the puerperium (Crohn et al., 1956; de Dombal et al., 1965). In Crohn's series, the lowest incidence of complications and colitis were during the second and third trimesters, when it might be expected that quiescence could be correlated with increased levels of endogenous hormones. De Dombal et al. (1965) observed that $47.5 \%$ of colitics of childbearing age and in remission, were likely to relapse within one year. It therefore seems that pregnancy does not increase the chance of relapse, but one in 3 of such patients would have to contend with both colitis and pregnancy. Of patients with colitis active at time of conception, $49 \%$ deteriorated and $70 \%$ failed to improve within the gestational period. There is general agreement between series that patients in Categories 3 and 4 are more likely to have severe colitis and a poor prognosis.

Maternal mortality is difficult to assess but mainly occurs in Categories 3 and 4. For these groups combined, the proportion of maternal deaths was $5-11 \%$, whereas for Categories 1 and 2, it was only $0 \cdot 2-0.7 \%$. However, Rice-Oxley and Truelove (1950) estimated that mortality from colitis, within the first year of the disease, was $22 \%$. It is possible that the above related as much to the disease as to pregnancy.

Management of colitis during pregnancy is essentially as in the non-pregnant subject. Conception should be encouraged whilst the patient is in remission and taking as few medications as possible. Investigations should be kept to a minimum, but gentle sigmoidoscopy is possible and barium enema should be avoided. Medical treatment is the same as for the non-pregnant patient and includes local and systemic steroids, and sulphasalazine. The latter has been useful in maintaining remission of colitis (Dissanayake and Truelove, 1973) and this has been suggested as the drug of choice during pregnancy (de Dombal et al., 1965). Other authors (Webb and Sedlack, 1974) disagree with this, since teratogenic effects have been observed in animals. They suggested that steroids should be used, but not in the first trimester because of possible effects on the fetus.
Rectal steroids and ACTH can be used to treat relapses occurring in pregnancy. The incidence of fetal abnormality with prednisolone is controversial, although animal work has suggested this (Nelson and Forfar, 1971). Adrenal suppression of the neonate has not been reported and if the dose of prednisolone is less than $20 \mathrm{mg} /$ day, there is no interference with maternal oestrogen excretion, so this may still be used to assess fetal function. Other agents, such as disodium cromoglycate (Nalcrom) appear harmless in pregnancy, but its efficacy in the treatment of colitis is in doubt.

Few patients had severe colitis needing surgery during pregnancy, but when necessary the prognosis for mother and fetus was not good (McEwan, 1972). This author even suggested that there were grounds for termination of the pregnancy whilst the colitis was severe and encouraging the patient to conceive after surgery. Toxic dilatation of the colon was a rare complication in pregnancy, but also had a poor prognosis (Becker, 1972). In the puerperium, sulphasalazine could be restarted (if it has not been given during pregnancy) since less than $30 \%$ of the normal dose is excreted in breast milk and no teratogenic effects have been observed in animals with this dose (A. D. Tumer, unpublished observations, 1978).

One further point to mention is the measurement of oestriol levels as markers for placental function in patients with colitis. These patients and others with diarrhoea show similar features to patients treated with ampicillin and have abnormally low oestriol excretion. This is probably secondary to a reduction in oestriol absorption and reduced bacterial deconjugation of oestriol glucuronide, which is therefore excreted in faeces and not reabsorbed for excretion in urine (Trolle, Pedersen and Gaede, 1977). In these situations, low oestriol levels may incorrectly indicate placental dysfunction.

\section{Crohn's disease}

The literature is at variance on the subject of reduced fertility in this disease. Crohn's series (Crohn et al., 1956) showed no change in fertility in contrast to Fielding and Cooke (1970) who found that in a study of 77 patients, $32 \%$ failed to conceive. De Dombal, Burton and Goligher (1972) also showed subfertility with 46 out of 86 patients $(53.5 \%)$ who were unsuccessful in achieving a pregnancy. Difficulty in conception was more frequent in Crohn's colitis $(60 \%)$ than with small bowel disease $(26 \%)$. Further studies have suggested that reduced fertility showed no relation to the site of the disease (Homan and Thorbjarnarson, 1976). In some cases, improvement in nutritional status improved conception while some cases showed no change because mechanical obstruction of the fallopian tube occurred secondary to the disease. 
It is generally accepted that Crohn's disease does not adversely affect mother or cinild (Fielding and Cooke 1970; de Dombal et al., 1972; Norton and Patterson, 1972). In Miller's review of 264 normal term deliveries in 337 pregnancies $(78 \%)$, there were $45(13 \%)$ miscarriages, 1 stillbirth and 3 fetal abnormalities. Other series showed that some pregnancies ended with fetal death or abnormality (Schofield, Turnbull and Hawk, 1970).

The effect of pregnancy upon the course of the disease may be considered in the same categories as described for colitis. In Category 1 , disease inactive at conception, a relapse occurred in $20(26 \%)$ out of 77 patients (Homan and Thorbjarnarson, 1976). In Category 2, disease active at conception, only 5 patients out of $40(12.5 \%)$ relapsed. Although only few cases in Categories 3 and 4 are discussed in the literature, Martimbleau, Welch and Weiland (1975) reviewed 10 cases with disease originating in pregnancy. They found a high incidence of fetal mortality and incidence of surgery for the mother. Fielding and Cooke (1970) did not note any differences in general health between pregnant and non-pregnant patients with Crohn's disease. If deterioration occurred, as with colitis, it was commonest in the puerperium (de Dombal et al., 1972). Some patients actually improved during the gestational period. Authors of both latter series agreed that patients who had undergone surgery before pregnancy suffered fewer problems, but were probably less likely to have active disease.

Management of the disease in pregnancy is essentially as for the non-pregnant subject. Patients should be encouraged to conceive when the disease is controlled, and correction of nutritional deficiencies may improve fertility. Because of the tendency to relapse in the puerperium, use of prophylactic steroid is advocated by some (de Dombal et al., 1972) but not by others (Fielding, 1976).

Finally, turning to the question of the use of sulphasalazine, azathiaprine and steroids in liver and gastrointestinal diseases: maternal steroid treatment and its effects have been reviewed by Bongiovanni and McPadden (1960) who concluded that they were safe for the fetus. This has been supported by studies in other situations, such as asthma, where steroids have been administered throughout pregnancy (Schatz et al., 1975). In a study of 34 pregnant subjects taking steroids throughout pregnancy, Warrell and Taylor (1968) found 8 stillbirths, 2 anencephalics, whereas only one stillbirth occurred in the nonpregnant controls. Azathiaprine, given for its steroidsparing effect in Crohn's disease, should not be used in pregnancy because of its teratogenic effects in animals. However, in 3 patients with systemic lupus erythematosus taking azathiaprine $(2.5 \mathrm{mg} / \mathrm{kg}$ body weight), 4 normal infants were delivered (Miller,
1977). Sulphasalazine is still advocated by some during pregnancy, since it is important to both mother and child that the colitis remains in remission. Nelson and Forfar (1971) have reported fetal abnormalities in mothers taking sulphonamides during pregnancy but these have also occurred with a wide variety of other drugs.

\section{Conclusion}

It can be seen that normal pregnancy has a marked effect upon the normal liver and gastrointestinal system as well as upon the diseased organs. Discussion of pregnancy and pre-existing liver disease has not been discussed here, but has been reviewed elsewhere (Miller, 1977; Walshe, 1977; Cheng, 1977). However, the field is wide open for further research and the major problem lies in overcoming the difficulties of investigation with the fetus in situ.

\section{References}

Adlercreutz, H. \& Tenhunen, R. (1970) Some aspects of the interaction between natural and synthetic female sex hormones and the liver. American Journal of Medicine, 49, 630.

Atkinson, R.E. \& Hudson, C.N. (1970) Ano-rectal and perineal disorders of pregnancy and the puerperium. Practitioner, 205, 789.

Avery-Jones, F. \& Gummer, J.W. (1960) Clinical Gastroenterolog , p. 43. Blackwell Scientific Publications, Oxford. Bean, W.B., Cogswell, R., Deter, M. \& Embick, J.F. (1949) Vascular changes of the skin in pregnancy. Surgery, Gynecology and Obstetrics, 88, 739.

BeCker, I.M. (1972) Pregnancy and toxic dilatation of the colon. American Journal of Digestive Diseases, 17, 79.

Bennion, L.J., Ginsberg, R.L., Garnick, M.B. \& Bennett, P. (1976) Effects of oral contraceptives on the gallbladder bile of normal women. New England Journal of Medicine, 294, 189.

Bonglovanni, A.M. \& McPadden, A.J. (1960) Steroids during pregnancy and possible fetal consequences. Fertility and Sterility, 11, 181.

Borhanmanesh, F., Haghighi, P., Hekmat, K., Rezaizadeh, K. \& Ghavami, A.G. (1973) Viral hepatitis during pregnancy. Severity and effect on gestation. Gastroenterology, 64, 304.

Breen, K.J., Perkins, K.W., Mistilis, S.P. \& Shearman, R. (1970) Idiopathic acute fatty liver of pregnancy. Gut, 11, 822.

Breen, K.J., Perkins, K.W., Shenker, S., Dunkerley, R.C. \& Moore, H.C. (1972) Uncomplicated subsequent pregnancy, after idiopathic fatty liver of pregnancy. Obstetrics and Gynecology, 40, 813.

Cano, R.I., Delman, M.R., Pitchumoni, C.S., Lev, R. \& Rosenthal, W.S. (1975) Acute fatty liver of pregnancy. Journal of the American Medical Association, 231, 159.

Cheng, Y.S. (1977) Pregnancy in liver cirrhosis and/or portal hypertension. American Journal of Obstetrics and Gynecology, 128, 812.

Clark, D.H. (1953) Peptic ulcer in women. British Medical Journal, 1, 1254.

Combes, B., Shibata, H., Adams, R., Mitchell, B.D. \& Trammell, V. (1963) Alterations in sulfabromophthalein sodium-removal mechanisms from blood during normal pregnancy. Journal of Clinical Investigation, 42, 1431. 
Crawford, J.S. \& Hool, H.W.Y. (1968) Binding of bromsulphthalein by serum albumin from pregnant women, neonates and subjects on oral contraceptives. British Journal of Anaesthesia, 40, 723.

Crohn, B.B., Yarnis, H., Crohn, E.B., Walter, R.I. \& Gabrilove, L.J. (1956) Ulcerative colitis and pregnancy. Gastroenterology, 30, 391.

De Dombal, F.T., Burton, I.L. \& Goligher, J.C. (1972) Crohn's disease and pregnancy. British Medical Journal, 3, 550 .

de Dombal, F.T., Watts, J.M., Watkinson, G. \& Goligher, J.C. (1965) Ulcerative colitis and pregnancy. Lancet, ii, 599.

de Pagter, A.G.F., van Berge Henegouwen, G.P., Ten Bokkel Huinink, J.A. \& Brandt, K-H. (1976) Familial benign recurrent intrahepatic cholestasis. Gastroenterology, 71, 202.

Dissanayake, A.S. \& Truelove, S.C. (1973) A controlled therapeutic trial of long-term maintenance treatment of ulcerative colitis with sulphasalazine (Salazopyrin). Gut, 14, 923.

DrILL, V.A. (1974) Benign cholestatic jaundice of pregnancy and benign cholestatic jaundice from oral contraceptives. American Journal of Obstetrics and Gynecology, 119, 165.

Duma, R.J., Dowling, E.A., Alexander, H.C., Sibrans, D. \& Dempsey, H. (1955) Acute fatty liver of pregnancy. Annals of Internal Medicine, 63, 851 .

FIELDING, J.F. (1976) Inflammatory bowel disease and pregnancy. British Journal of Hospital Medicine, 15, 345.

Fielding, J.F. \& Cooke, W.T. (1970) Pregnancy and Crohn`s disease. British Medical Journal, 2, 76.

Fisher, R.S., Roberts, G.S., Grabowski, C.J. \& Cohen, S. (1976) Heartburn of pregnancy: a hormonal disorder (abstract). Clinical Research, 24, 284A.

Friedman, M.M. \& LAPAN, B. (1961) Variation of enzyme activities during normal pregnancy. American Journal of Obstetrics and Gynecology, 82, 132.

Haemmerli, U.P. (1966) Jaundice during pregnancy. Acta medica scandinavica, 444 (Suppl.), 23.

Homan, W.P. \& Thorbjarnarson, B. (1976) Crohn disease and pregnancy. Archives of Surgery, 111, 545.

HuChzermeyer, H. (1971) Pregnancy in patients with liver cirrhosis and chronic hepatitis. Acta hepatosplenologica. Stuttgart, 18, 294.

Hytten, F.E. \& Leitch, I. (1971) The Physiology of Human Pregnancy. 2nd edn. Blackwell Scientific Publications, Oxford.

Ingersley, M. \& Teilum, G. (1945) Biopsy studies on the liver in pregnancy. Acta obstetrica et gynecologica scandinavica, 25, 339.

Joske, R.A. \& Martin, J.D. (1971) Coeliac disease presenting as recurrent abortion. Journal of Obstetrics and Gynaecology of the British Commonwealth, 78, 754.

KUMAR. D. (1962) In vitro inhibitory effect of progesterone on extrauterine human smooth muscle. American Journal of Obstetrics and Gynecologv, 84, 1300.

Kunelis, C.T., Peters, J.L. \& Edmundson, H.A. (1965) Fatty liver of pregnancy and its relationship to tetracycline therapy. American Journal of Medicine, 38, 359.

LAATIKAINEN, T.J. (1975) Fetal bile acid levels in pregnancies complicated by maternal intrahepatic cholestasis. American Journal of Obstetrics and Gynecology, 122, 852.

LANGMADE, C.F. (1956) Epigastric pain in pregnancy toxemias. Western Journal of Surgery, 64, 540.

Levy, N., Lemberg, E. \& Sharf, M. (1971) Bowel habit in pregnancy. Digestion, 4, 216.

Lin, T-M., Halbert, S.P., Spellacy, W.N. \& Berne, B.H. (1977) Plasma concentrations of four pregnancy proteins in complications of pregnancy. American Journal of Obstetrics and Gynecology, 128, 808.
LynN, J., Williams, L., O’Brien, J., Wittenberg, J. \& EgDaHL, R.H. (1973) Effects of oestrogen upon bile. Annals of Surgery, 178, 514.

MCEWAN, H.P. (1972) Ulcerative colitis in pregnancy. Proceedings of the Royal Society of Medicine, 65, 279.

MCNAIR, R.D. \& JAYNES, R.V. (1960) Alterations in liver function during normal pregnancy. American Journal of Obstetrics and Gynecology, 80, 500.

MADDIX, B.L. (1962) Ulcerative colitis and pregnancy. Minnesota Medicine, 45, 1097.

Martimbleau, P.W., Welch, J.S. \& Weiland, L.H. (1975) Crohn's disease and pregnancy. American Journal of Obstetrics and Gynecology, 122, 746.

Martin, R.H., Harper, T.A. \& Kelso, W. (1965) Serum folic acid in recurrent abortions. Lancet, i, 670.

Miller, J.P. (1977) Diseases of the liver and alimentary tract. Clinics in Obstetrics and Gynecology, 4, 297.

Morris, J.S., Adjukiewicz, A.B. \& ReAd, A.E. (1970) Coeliac infertility: an indication for dietary gluten restriction? Lancet, i, 213.

Mueller, M.N. \& KaPPAS, A. (1964) Estrogen pharmacology. I. The influence of estradiol and estriol on hepatic disposal of sulfobromophthalein (BSP). Journal of Clinical Investigation, 43, 1905.

Nelson, M.M. \& Forfar, J.O. (1971) Association between drugs administered during pregnancy and congenital abnormalities of the foetus. British Medical Journal, 1, 523.

Norton, R.A. \& Patterson, J.F. (1972) Pregnancy and regional enteritis. Obstetrics and Gvnecology, 40, 711.

Ober, W.B. \& Le Compte, P.M. (1955) Acute fatty metamorphosis of the liver associated with pregnancy: a distinctive lesion. American Journal of Medicine, 19, 743.

OCKNeR, R.K. \& Davidson, C.S. (1967) Hepatic effects of oral contraceptives. New England Journal of Medicine, 276, 331 .

OGborn, A.D.R. (1975) Pregnancy in patients with coeliac disease. British Journal of Obstetrics and Gynaecology, 82, 293.

Okada, K., Kamiyama, I., Inomata, M., Imai, M., MiyaKaWA, Y. \& Mayumi, M. (1976) Antigen and anti-e in the serum of asymptomatic carrier mothers as indicators of positive and negative transmission of hepatitis $B$ virus to their infants. New England Journal of Medicine, 294, 746.

Perez, V. \& Gorodisch, S. (1974) Female sex hormones and the liver. In: The Liver and its Diseases. (Ed. by Schaffner, F., Sherlock, S. \& Leevy, C.M.) p. 179. Georg Thieme Publishers, Stuttgart.

Perez, V., Gorodisch, S., Casavilla, F. \& Maruffo, C. (1971) Ultrastructure of human liver at the end of normal pregnancy. American Journal of Obstetrics and Gynecology. $110,428$.

Peters, R.L., Edmundson, H.A., Mikkelsen, W.P. \& TATTER, D. (1967) Tetracycline-induced fatty liver in nonpregnant patients. American Journal of Surgery, 113, 622.

Reid, R., Ivey, K.J., Rencoret, R.H. \& Storey, B. (1976) Foetal complications of obstetric cholestasis. British Medical Journal, 1, 870.

Reyes, H., Ribalta, J. \& González-Cerón, M. (1976) Idiopathic cholestasis of pregnancy in large kindred. Gut, 17, 709.

Rice-OxLey, J.M. \& Truelove, S.C. (1950) Ulcerative colitis, course and prognosis. Lancet, i, 663.

Romslo, I., Sagen, N.R. \& Haram, K. (1975) Serum alkaline phosphatase in pregnancy. Acta obstetrica et gynecologica scandinavica, 54, 437.

Rotthauwe, H.W. (1974) Clinics in Gastroenterology, vol. 3. p. 447. W. B. Saunders, London.

Sampliner, R.E., Bennet, P.H., Comess, L.J., Rose, F.A. \& BurCh, T.A. (1970) Gallbladder disease in Pima Indians. New England Journal of Medicine, 283, 1358. 
Schatz, M., Patterson, R., Zeitz, S., O'Rourke, J. \& Merlam, H. (1975) Corticosteroid therapy for the pregnant asthmatic patient. Journal of the American Medical Association, 233, 804.

Schofield, P.F., Turnbull, R.B. \& Hawk, W.A. (1970) Crohn's disease and pregnancy. British Medical Journal, 2, 364.

Schweitzer, I.L., Dunn, A.E.G., Peters, R.L. \& Spears, R.L. (1973) Viral hepatitis $B$ in neonates and infants. American Journal of Medicine, 55, 762.

Sheeran, H.L. (1940) The pathology of acute yellow atrophy and delayed chloroform poisoning. Journal of Obstetrics and Gynaecology of the British Empire, 47, 49.

SHERLOCK, S. (1968) Jaundice in pregnancy. British Medical Bulletin, 24, 39.

SHERLOCK, S. (1975) Diseases of the Liver and Biliary System, ch. 7. Blackwell Scientific Publications, Oxford.

Skinhoj, P., Cohn, J. \& Bradburne, A.F. (1976) Transmission of hepatitis type B from healthy HBsAg-positive mothers. British Medical Journal, 1, 10.

SuMmerskill, W.H.J. \& WALSHE, J.M. (1959) Benign recurrent intrahepatic "obstructive" jaundice. Lancet, ii, 686.

Sussman, H.H., Bowman, M. \& Lewis, J.L. (1968) Placental alkaline, phosphatase in maternal serum during normal and abnormal pregnancy. Nature. London, 218, 359.

Trolle, D., Pedersen, S.N. \& Gaede, P. (1977) Oestriol concentrations in urine and serum in patients with various intestinal diseases. Acta obstetrica et gynecologica scandinavica, 56, 347

TRYelOVE, S.C. (1960) Stilboestrol, phenobarbitone and diet in chronic duodenal ulcer. British Medical Journal, 2, 559.
TURRell, R. (1969) Obstetric and gynecologic considerations. In: Diseases of the Colon and Anorectum 2nd Edn (Ed. by Turrell, R.), p. 1213. W. B. Saunders Co, Philadelphia.

Urban, E., Frank, B.W. \& Kern, F. (1968) Liver dysfunction with mestranol but not with norethynodrel in a patient with Enovid-induced jaundice. Annals of Internal Medicine, 68, 598.

VAN DER LINDEN, W. (1961) Some biological traits in female gallstone-disease patients. Acta chirurgica scandinavica 269 (Suppl.).

van Thiel, D.H., Gavaler, J.S., Joshi, S.N., Sara, R.K. \& Stremple, J. (1977). Heartburn of pregnancy. Gastroenterology, 72, 666.

Walker, F.B., Hoblit, D.L., Cunningham, F.G. \& Combes, B. (1974) Gammaglutamyl transpeptidase in normal pregnancy. Obstetrics and Gynecology, 43, 745.

WALShe, J.M. (1977) Pregnancy in Wilson's disease. Quarterly Journal of Medicine, 46, 73.

WARRELL, D.W. \& TAYLOR, R. (1968) Outcome for the foetus of mothers receiving prednisolone during pregnancy. Lancet, 1, 117.

Webb, M.J. \& Sedlack, R.E. (1974) Ulcerative colitis in pregnancy. Medical Clinics of North America, 58, 823.

Wetstone, H.J., La MotTa, R.V., MiddlebrooK, L., TenNant, R. \& White, B.V. (1958) Studies of cholinesterase activity. IV. Liver functions in pregnancy. Values of certain standard liver function tests in normal pregnancy. American Journal of Obstetrics and Gynecology, 76, 480. 